\title{
Effectiveness of brace treatment for adolescent idiopathic scoliosis
}

\author{
Toru Maruyama*, Yosuke Kobayashi, Makoto Miura, Yusuke Nakao \\ From 10th International Research Society of Spinal Deformities (IRSSD) \\ Sapporo, Japan. 29 June - 2 July 2014
}

\begin{abstract}
Objectives: Effectiveness of brace treatment for adolescent idiopathic scoliosis (AIS) was demonstrated by the BrAIST study in 2013. Objectives of this study were to confirm its effectiveness by analyzing our results and to clarify the factors affecting the results of the treatment.
\end{abstract}

Materials and methods: According to the Scoliosis Research Society AIS brace studies standardization criteria, patients with age 10 years or older, Risser 0 to II, less than 1 year post-menarche, curve magnitude 25 to 40 degrees before brace treatment and who received no prior treatment were included in the study. At skeletal maturity, the rate of the patients whose curve was stabilized, exceeded 45 degrees, and who were recommended or underwent surgery were investigated. Additionally, initial correction rate by the brace and factors affecting the results were investigated.

Results: A total of 33 patients (27 females and 6 males) could be followed-up until their skeletal maturity and included in the analysis. An average age was 11.9 years, average Cobb angle was 30.8 , and Risser sign was 0 in 13 patients, I in 5, and II in 15 patients before treatment. There were 13 thoracic curves, 14 thoracolumbar or lumbar curves, and 6 double curves. Initial correction rate by the brace was $53.8 \%$ for the total curves. In terms of curve pattern, $34.4 \%$ for thoracic curve, $73.9 \%$ for thoracolumbar or lumbar curve, and $48.8 \%$ for double curve. After an average follow-up period of 33 months, 8 patients improved in more than 6 degrees, change of 17 patients were within 6 degrees, and 8 progressed in more than 6 degrees. Therefore, totally, $76 \%(25 / 33)$ of the curves were stabilized by the treatment. Four curves (12\%) exceeded 45 degrees and one patient (3\%) underwent surgery. Our results were better than the reported natural history. Factors that affected the results were hump degree before treatment and initial correction rate by the brace.

Conclusions: $76 \%$ of the curve with AIS could be stabilized by brace treatment. Brace treatment was effective for treatment of AIS. Factors affecting the results were hump degrees and initial correction rate.

\section{Background}

Effectiveness of brace treatment for AIS was demonstrated by BrAIST study in 2013 [1]. Purpose of this study was to certify the effectiveness of brace treatment by analyzing our treatment results and to clarify the factors affecting the results of the treatment.

\section{Materials and methods}

With Institutional Review Board of Saitama Medical Center approval, we retrospectively reviewed the

\footnotetext{
* Correspondence: Tmaruyama58@yahoo.co.jp

Department of Orthopaedic Surgery, Saitama Medical Center, Saitama Medical University, 1981 Kamoda, Kawagoe, Saitama, 350-8550 Japan
}

prospective database that started in April 2007. According to the SRS brace studies standardization criteria [2], AIS patients with age 10 years or older, Risser 0 to 2, pre-menarche or less than 1 year post-menarche, curve magnitude 25 to 40 degrees before brace treatment and who received no prior treatment were included in the study. The rate of the patients whose curve was stabilized, exceeded 45 degrees, and who were recommended or underwent surgery at skeletal maturity was investigated. Stabilization of the curve was defined as the curve not progressed in more than 6 degrees at skeletal maturity comparing with the pre-treatment Cobb angle. 
Additionally, initial correction rate by the brace was calculated comparing pre-treatment Cobb angle and first in-brace $\mathrm{Cobb}$ angle. Factors affecting the results were analyzed by single variable analysis. In the statistical analysis, Student t-test was used for continuous variables and chi-square test was used for discontinuous variables. A p-value of less than 0.05 was considered to be significant.

\section{Description of the brace system and treatment protocol}

We have been using Rigo-Chêneau type brace (Figure 1). When brace treatment is indicated, plaster molding is done with the patient in the standing position. The patient is instructed to shift her trunk to the concavity of the curve while molding in order to locate her/his thoracic cage properly on the pelvis. One week after, trial fitting is conducted and the first in-brace radiograph is taken. The brace is adjusted and completed one more week after. Two to three months after completion of the brace, second in-brace radiograph is taken and the brace is adjusted if necessary.

\section{Results}

A total of 33 patients were included in the analysis. Patients' demographic characteristics were shown in Table 1.

Initial correction rate of the total curves were $53.8 \%$. In terms of curve pattern, $34.4 \%$ for thoracic curve, $73.9 \%$ for thoracolumbar or lumbar curve, and $44.8 \%$ for double curve.

After an average follow-up period of 33 months, all the patients had reached skeletal maturity. No patients were dropped out or lost to follow-up during the study period. Of 33 patients, 8 improved in more than 6 degrees, change of 17 patients were within 6 degrees, and 8 progressed in more than 6 degrees. Therefore, totally $75.8 \%(25 / 33)$ of the curves were stabilized by the treatment. Four curves (12\%) exceeded 45 degrees and one patient (3\%) underwent surgery.

Factors affecting the results, whether the curve was improved or progressed, were hump degrees before treatment and initial correction rate by the brace (Table 2). In other words, better results were predicted for patients with smaller hump degrees, or the patients with better

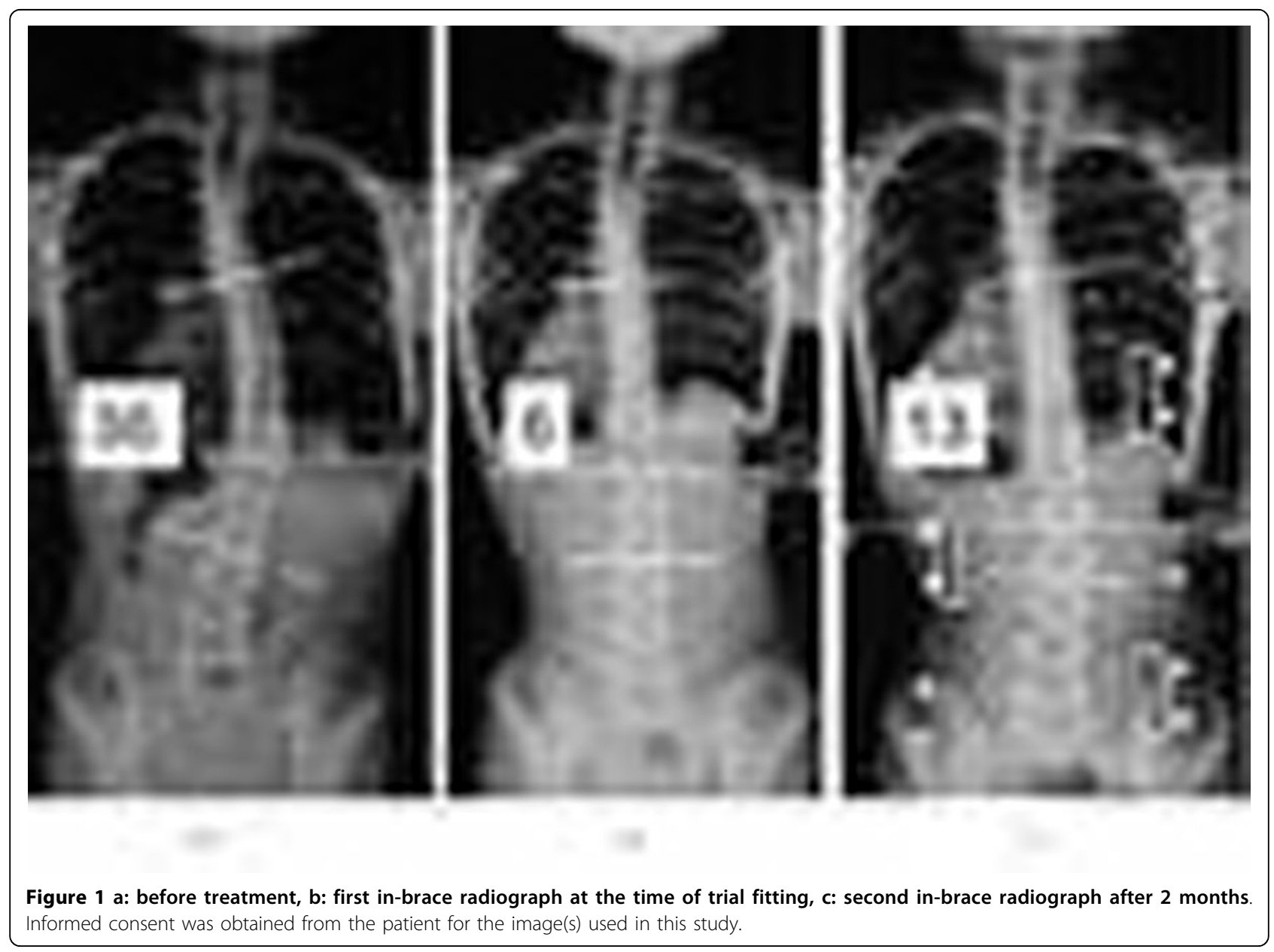


Table 1 Patients' demographic characteristics

\begin{tabular}{lll}
\hline Gender (number) & Female & 27 \\
\hline Age (year) & Male & 6 \\
\hline Cobb angle (degree) & $11.9 \pm 1.2$ & \\
\hline Risser sign (number) & $30.8 \pm 4.7$ & 13 \\
\hline & 0 & 5 \\
\hline Curve pattern (number) & I & 15 \\
\hline & Thoracic & 13 \\
\hline & Doracolumbar or lumbar & 14 \\
\hline
\end{tabular}

initial correction rate. Other factors had no statistically significant effect on the results.

\section{Discussion}

Results of this study showed that $76 \%$ of the curves with AIS patients who met the SRS inclusion criteria were stabilized by the brace treatment. These results were compared with natural history and other brace studies using the SRS standardization criteria (Table 3).

In the natural history, $33 \%$ or $34 \%$ of the curve had not progressed $[3,4]$, which were much lesser than our results. Other brace studies indicated a wide range of stabilization rate, $15 \%$ to $96 \%$ [5-9]. Our results were better than most of these studies, even though some of these studies excluded dropped-out patients from analysis.

Results of this study indicated that hump degree and initial correction rate affected the results of the brace treatment. When the number of the patients analyzed will increase, Risser sign or curve pattern may become a predictive factor. Although some studies showed that compliance of the patient was a predictive factor $[1,10]$, we could not include it in the analysis because we had no objective measuring device. Further study will be required with increasing number of the patients and additional factors such as compliance and thoracic kyphosis.

Table 2 Factors affecting the results

\begin{tabular}{llll}
\hline & Improved $(\mathrm{n}=8)$ & Progressed $(\mathrm{n}=8)$ & \\
\hline Gender & Female 6, Male 2 & Female 6, Male 2 & $>0.9999$ \\
\hline Age & $11.5 \pm 1.4$ & $12.1 \pm 1.1$ & 0.3447 \\
\hline Risser sign & 0 2, I 1, II 5 & 0 6, I 1, II 1 & 0.0819 \\
\hline Curve pattern & T 2, TL or L 5, D 1 & T 4, TL or L 1, D 3 & 0.0984 \\
\hline Cobb (degree) & $29.4 \pm 4.5$ & $31.9 \pm 4.6$ & 0.2911 \\
\hline Hump (degree) & $5.8 \pm 3.3$ & $9.8 \pm 2.8$ & $0.0204 *^{* 1}$ \\
\hline Correction (\%) & $83.4 \pm 30.2$ & $37.6 \pm 24.1$ & $0.0048 * 1$ \\
\hline
\end{tabular}

\footnotetext{
$*^{1}:$ statistically significant
}

Table 3 Comparison of our results, natural history, and other brace studies

\begin{tabular}{lllllll}
\hline Author & Year & Treatment & $N$ & Stabilize & $45^{\circ}<$ & Surgery \\
\hline Maruyama & 2014 & Rigo-Chêneau & 33 & $76 \%$ & $12 \%$ & $3 \%$ \\
\hline Bunnell [3] & 1986 & Natural history & NA & $33 \%$ & NA & NA \\
\hline Nachemson[4] & 1995 & Natural history & 129 & $34 \%$ & NA & NA \\
\hline Janicki[5] & 2007 & TLSO & 48 & $15 \%$ & $63 \%$ & $79 \%$ \\
\hline Gammon [6] & 2010 & TLSO & 35 & $60 \%$ & $28 \%$ & $23 \%$ \\
\hline & & SpineCor & 32 & $53 \%$ & $20 \%$ & $19 \%$ \\
\hline Coillard [7] & 2007 & SpineCor & 170 & $59 \%$ & $24 \%$ & $23 \%$ \\
\hline Lee [8] & 2012 & Charleston & 95 & $84 \%$ & $16 \%$ & $8 \%$ \\
\hline Negrini [9] & 2009 & Various & 46 & $96 \%$ & $0 \%$ & $0 \%$ \\
\hline
\end{tabular}

\section{Conclusion}

Seventy-six per cent of the curve with AIS could be stabilized by the brace treatment. Brace treatment was effective for the treatment of AIS. Factors that affected the results of the treatment were hump degree before treatment and initial correction rate by the brace.

This is the extended abstract of IRSSD 2014 program book [11].

\section{List of abbreviations used}

AIS: adolescent idiopathic scoliosis; BrAIST: bracing for adolescent idiopathic scoliosis trial; SRS: Scoliosis Research Society

\section{Competing interests}

We declare that we have no competing interests'.

\section{Authors' contributions}

YK, MM and YN participated in the design of the study and helped to collect data.

TM conceived of the study, participated in its design, performed the statistical analysis and helped to draft the manuscript.

All authors read and approved the final manuscript.

\section{Declarations}

Publication charges for this collection were funded by IRSSD 2014 Sapporo. This article has been published as part of Scoliosis Volume 10 Supplement 2, 2015: Research into Spinal Deformities 9: Short Papers from the IRSSD 2014 Meeting. The full contents of the supplement are available online at http:// www.scoliosisjournal.com/supplements/10/s2.

Published: 11 February 2015

\section{References}

1. Weinstein SL, Dolan LA, Wright JG, Dobbs MB: Effects of bracing in adolescents with idiopathic scoliosis. N Engl J Med 2013, 369:1512-1521.

2. Richards BS, Bernstein RM, D'Amato CR, Thompson GH: Standardization of criteria for adolescent idiopathic scoliosis brace studies. SRS Committee on Bracing and Nonoperative Management. Spine 2005, 30(18):2068-2075.

3. Bunnell WP: The natural history of idiopathic scoliosis before skeletal maturity. Spine 1986, 11(8):773-776.

4. Nachemson AL, Peterson LE: Effectiveness of treatment with a brace in girls who have adolescent idiopathic scoliosis. A prospective, controlled study based on data from the Brace Study of the Scoliosis Research Society. J Bone Joint Surg Am 1995, 77-A(6):815-822.

5. Janicki JA, Poe-Cohert C, Armstrong DG, Thompson GH: A comparison of the thoracolumbosacral orthoses and providence orthosis in the 
treatment of adolescent idiopathic scoliosis. J Pediatr Orthop 2007, 27(4):369-374

6. Gammon SR, Mehlman CT, Chan W, Heifetz J, Durrett G, Wall EJ: A comparison of Thoracolumbosacral orthoses and SpineCor treatment of adolescent idiopathic scoliosis patients using the Scoliosis Research Society standardized criteria. J Pediatr Orthop 2010, 30(6):531-538.

7. Colliard C, Vachon V, Circo AB, Beausejour M, Rivard CH: Effectiveness of the SpineCor brace based on the new standardized criteria proposed by the Scoliosis Research Society for adolescent idiopathic scoliosis. Pediatr Orthop 2007, 27(4):375-379.

8. Lee CS, Hwang CJ, Kim DJ, Kim JH, Kim YT, Lee MY, Yoon SJ, Lee DH Effectiveness of the Charleston night-time bending brace in the treatment of adolescent idiopathic scoliosis. J Pediatr Orthop 2012 32(4):368-372.

9. Negrini S, Atanasio S, Fusco C, Zaina F: Effectiveness of complete conservative treatment for adolescent idiopathic scoliosis (bracing and exercise) based on SOSORT management criteria: results according to the SRS criteria for bracing studies - SOSORT award 2009 winner. Scoliosis 2009, 4(19).

10. Landauer F, Wimmer C, Behensky H: Estimating the final outcome of brace treatment for idiopathic thoracic scoliosis at 6-month follow-up. Pediatr Rehabil 2003, 6(3-4):201-207.

11. Toru Maruyama, et al: Effectiveness of brace treatment for adolescent idiopathic scoliosis. Scoliosis 2015, 10(Suppl 1):062.

doi:10.1186/1748-7161-10-S2-S12

Cite this article as: Maruyama et al.: Effectiveness of brace treatment for adolescent idiopathic scoliosis. Scoliosis 2015 10(Suppl 2):S12.

\section{Submit your next manuscript to BioMed Central and take full advantage of:}

- Convenient online submission

- Thorough peer review

- No space constraints or color figure charges

- Immediate publication on acceptance

- Inclusion in PubMed, CAS, Scopus and Google Scholar

- Research which is freely available for redistribution

Submit your manuscript at www.biomedcentral.com/submit 